\title{
뜬침목구간에서 차량/케도 상호작용 수치해석기법 개발 \\ Development of a Numerical Method of Vertical Train/Track Interaction in the Track Section with Hanging Sleepers
}

\author{
양신추 ${ }^{1} \cdot$ 이지하 ${ }^{2 \dagger}$
}

Sin-Chu Yang · Jeeha Lee

\begin{abstract}
Hanging sleepers are frequently observed in the ballasted track with the rail of high rigidity. These hanging sleepers at the high speed line could cause such large dynamic force compared to those at the conventional line. This dynamic force would, in turn, deteriorate train running stability as well as riding comfort, and accelerate irregularity of track and failure of track materials, leading to a sharp increase in track maintenance cost. When the wheel-rail contact spring exhibits nonlinear behavior and some components of the system like hanging sleeper exhibit bi-linear behaviors, an effective analytical method is proposed for train-track interactions. The verification of the present method is carried out comparing numerical results by the present method and those by Ono's method of RTRI.
\end{abstract}

Keywords : Hanging sleeper, Train/track interaction, Subgrade settlement, Non-linear model, Track irregularity

초 록 고속철도 자갈궤도에서 궤도틀림을 체계적이고 효율적으로 관리하기 위해서는 뜬 침목구간에서 차량 이 궤도에 미치는 동하중의 특성을 파악할 필요가 있으며 이를 위해서는 뜬 침목을 고려한 차량과 궤도의 동적 상호작용해석기법의 개발이 필요하다. 본 연구에서는 초기 레일의 처짐이 없는 경우 궤광자중에 의하여 발생한 레일처짐(궤도틀림)과 처진 침목과 자갈도상간의 침목 들뜸량을 계산할 수 있는 해석기법을 개발하였고, 궤도틀 림과 침목 들뜸량을 동시에 고려할 수 있는 차량과 궤도의 해석기법을 개발하였다. 본 해석기법의 타당성은 타 문헌에서 제시한 해석결과와 비교를 통하여 검증하였다.

주요어 : 뜬침목, 차량/궤도 상호작용, 노반침하, 비선형 모형, 궤도틀림

\section{1. 서 론}

자갈궤도에 있어서 자갈의 불균질성에 의하여 뜬침목 현 상이 자주 발생하게 된다. 뜬침목은 기존선에서는 크게 문 제되지 않지만 고속철도에서는 기존철도와는 비교할 수 없 을 정도로 큰 충격력이 발생하여 궤도가 급격하게 변형됨으 로써 열차의 주행안전성과 승차감이 심각하게 저하되고 궤 도 구성품의 열화 및 손상이 촉진된다. 현재 경부고속철도 의 궤도틀림은 주로 뜬 침목형태로 발생하고 있으며 이를 보 수하기 위하여 많은 인력과 비용이 투입되고 있는 실정이다. 따라서 고속철도 자갈궤도에서 궤도틀림을 체계적이고 효율 적으로 관리하기 위해서는 뜬침목 구간에서 차량이 궤도에 미치는 동하중의 특성을 파악할 필요가 있으며 이를 위해서 는 뜬침목을 고려한 차량과 궤도의 동적 상호작용해석기법 의 개발이 필요하다.

시계열 영역에서 차량과 궤도의 상호작용해석기법은 차륜 과 레일의 비선형 접촉특성과 궤도구성품의 비선형 거동특 성 및 국부적 궤도의 물성치 및 제원의 변화 등을 잘 고려

†교신저자 : 한국철도기술연구원 신교통연구본부

E-mail : jhlee@krri.re.kr

1한국철도기술연구원 고속철도연구본부

2한국철도기술연구원 신교통연구본부
할 수 있는 장점이 있어 최근까지 많은 연구가 진행되어 오 고 있다.

이들 대부분의 연구에서는 차륜과 레일의 접촉스프링은 비 선형적으로 거동하고 궤도구성품은 선형적으로 거동한다고 가정하여 해석을 수행하였다[1-7]. 그러나 뜬침목 구간에서 차량과 궤도의 상호작용을 정확하게 해석하기 위해서는 차 륜과 레일간의 비선형 접촉특성은 물론 침목이 자갈도상과 분리 또는 접촉하게 됨으로서 변화되는 침목과 자갈도상간 에 비선형 접촉특성을 고려하는 것이 매우 중요하다고 할 수 있다.

Lundqvist 등 [8]은 상용 유한요소해석프로그램 LS-DYNA 를 사용하여 차량을 1 질점의 이동질량으로 모델링하고 하부 의 궤도구성요소를 3 차원 솔리드요소(Solid element)로 모델 링하여 뜬침목에 따른 침목과 자갈도상의 접촉하중 발생특 성에 대한 연구를 수행하였다. 이 밖에 보다 정교한 차량 및 궤도의 해석모델(차량 1 량을 3 차원으로 모델링하고, 궤도를 레일, 침목, 그리고 도상자갈로 구성된 3층 모델)을 사용하 여 뜬 침목구간에서의 궤도의 동적거동 특성에 대한 연구실 적 $[9,10]$ 이 보고된 바 있다. 이들 연구에서는 단순히 침목과 자갈도상의 침목 들뜸량(침목과 자갈도상과의 높이차)을 가정 하여 차량과 궤도의 상호작용을 해석한 것으로서 뜬침목이 발생할 경우 궤광자중에 의하여 발생하는 궤도틀림은 고려 
되지 않았다. 한편 Ono 등[11]은 뜬 침목에 따른 궤도틀림 과 침목 들뜸량을 동시에 고려할 수 있는 차량과 궤도의 상 호작용 해석기법을 개발하였으며, 개발된 해석기법을 사용 하여 뜬 침목구간의 궤도틀림의 진전예측을 수행하였다.

본 연구에서는 초기 레일이 처짐이 없는 경우의 레일 레 벨과 도상자갈간의 높이차 즉, 침목 들뜸량이 주어질 경우 궤광자중에 의하여 발생한 레일처짐(궤도틀림)과 처진 침목 과 자갈도상간의 침목 들뜸량을 계산할 수 있는 해석기법을 통하여 궤도틀림과 침목 들뜸량을 동시에 고려할 수 있는 차 량과 궤도의 해석기법을 개발하였다. 본 해석 기법은 양신 추 $[12,16]$ 에 의해 개발된 수직방향 차량/궤도 상호작용 해석 기법의 알고리듬을 대부분 동일하게 적용하되 뜬 침목구간 의 비선형 접촉스프링을 고려할 수 있도록 해석기법을 수정 보완하였다. 따라서 본 해석기법은 문헌[12]에서 제시한 해 석시간의 단축 및 정확도의 향상 등의 장점을 유지한다. 본 해석기법은 궤도틀림과 침목 들뜸량을 동시에 고려할 수 있 는 측면에서 Ono등 [11]의 연구와 비슷하지만 Ono 등은 차 량을 반차체로 모델링한 반면 본 연구에서는 차량 1 량 전 체를 모델링함으로서 넓은 범위에서 뜬침목이 발생할 경우 차량의 피칭모션(Pitching Motion) 이 고려될 수 있도록하여 정확도는 높였다고 할 수 있다. 또한 Ono 등이 궤도를 모 드중첩법(Mode superposition)으로 모델링함으로써 고주파 충격진동을 해석하는데 많은 시간이 소요됨에도 정확도가 떨 어지는 것에 반하여 본 연구에서는 $\mathrm{FE}$ (Finite Element)로 직 접모델링함으로써 해석결과를 향상시켰다고 할 수 있다. 본 해석기법의 타당성은 Ono 등 [11]의 연구의 예제해석 결과 를 비교함으로써 검증하였다.

\section{2. 수치해석모델}

\section{1 차량과 궤도의 상호작용 해석모델}

Fig. 1은 뜬 침목구간에서의 차량과 궤도의 상호작용해석 모델을 나타낸다. 차량모델은 차체(Car body)와 2개의 대차
(Bogie), 그리고 4개의 윤축(wheelset)으로 구성되며, 이들은 각각 강체운동을 하는 것으로 가정하여 질점(lumped mass) 으로 모델링하였다. 또한 차체와 대차를 연결하는 2 차 현수 장치와 대차와 윤축을 연결하는 1차 현수장치는 스프링과 감 쇠 요소(damping element)로 모델링하였다. 차량은 수직운 동만 하는 것으로 가정하여 10 개의 자유도 시스템으로 나 타낸다. 이 경우 차량 시스템의 강성, 감쇠, 그리고 질량 행 렬은 문헌[13,14]에서 제시한 것과 같은 방법으로 구성할 수 있다.

궤도 서브모델은 자갈궤도의 레일, 레일체결장치, 침목, 도 상자갈(ballast), 그리고 노반 등이 다층(multi layers)으로 배 열된 것으로 모형화하였다. 최상부층을 구성하는 레일은 Timoshenko 연속보로 모델링하였다. 하부의 레일체결장치 및 패드는 질점, 선형스프링(linear spring) 및 댐퍼(damper)로, 침목은 질점(mass)으로만 나타낸다. 도상자갈은 상층자갈, 중 층자갈, 하층자갈 등 3 층으로 분리하여 모델링하였다. 자갈 도상 각 층의 질량 및 강성의 평가방법은 다음과 같다.

침목하면 자갈도상의 응력분포는 실험 및 해석에 의하여 Fig. 2와 같이 가정할 수 있다. 즉 침목하면으로부터 $15 \mathrm{~cm}$ 까지는 침목하면 응력과 같고, 그 이상의 깊이에서는 $45^{\circ}$ 로 확산된다는 것이다. 이러한 가정을 토대로, 도상을 탄성체로 가정할 경우 각 증의 질량은 식 (1)과 같이, 그리고 강성은 식 (2)와 같이 구할 수 있다.

$$
\begin{aligned}
& m_{3}=\frac{b \times 1}{2} \times\left(7.5 \times 10^{-2}\right) \times \rho, m_{4}=m_{3}, \quad m_{5}=\frac{h_{h}}{12} \times z_{2} \times \rho \\
& k_{2}=\frac{E \times b \times 1}{7.5 \times 10^{-2}}, \quad k_{3}=\frac{k_{2}}{2}, \quad k_{4}=\frac{d_{k 1} \times d_{k 2}}{d_{k 1}+d_{k 2}}, \quad k_{5}=\frac{d_{k 4} \times d_{k 5}}{d_{k 4}+d_{k 5}}
\end{aligned}
$$

여기서 $b, 1$ 은 각각 침목 폭 및 길이이며, $\rho$ 및 $E$ 는 각각 도 상자갈의 단위밀도 및 탄성계수이고, $h$ 는 도상깊이이다. 식 (1), 식 (2)에서 나타나는 변수들은 다음 같이 구할 수 있다.

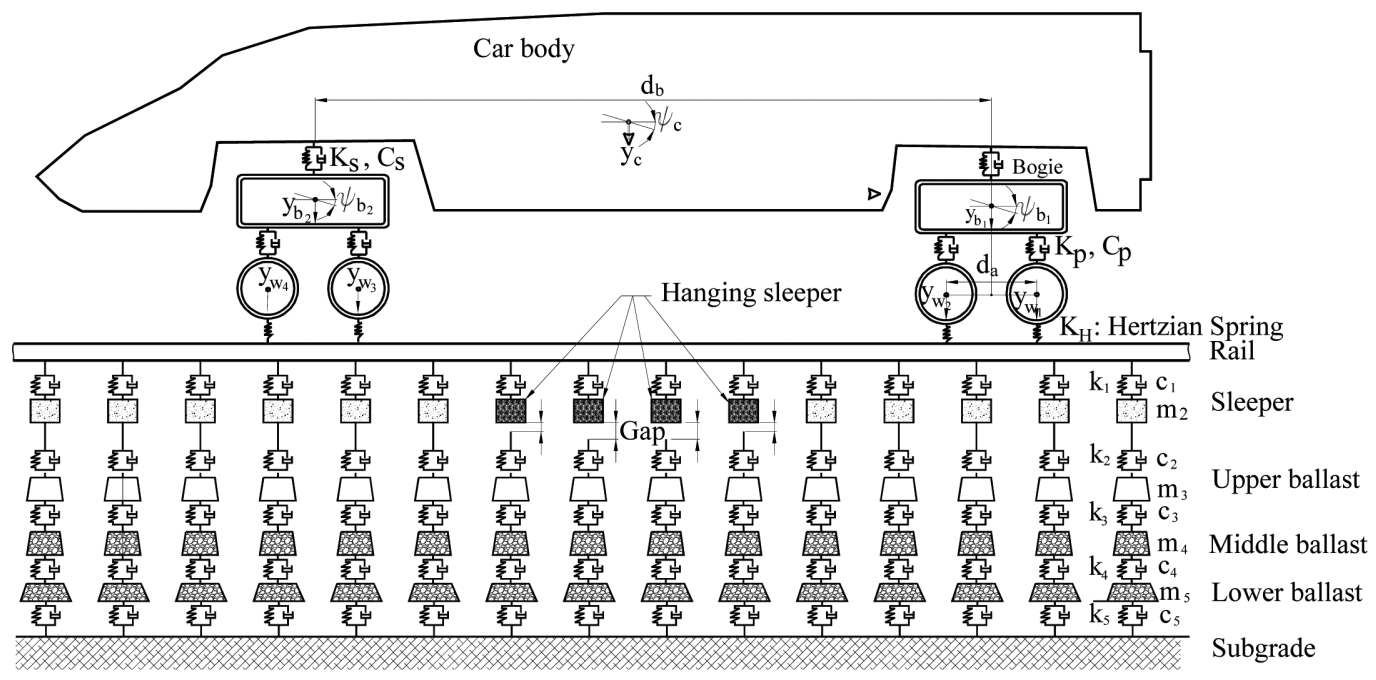

Fig. 1 Numerical model for the vertical train/track interaction 


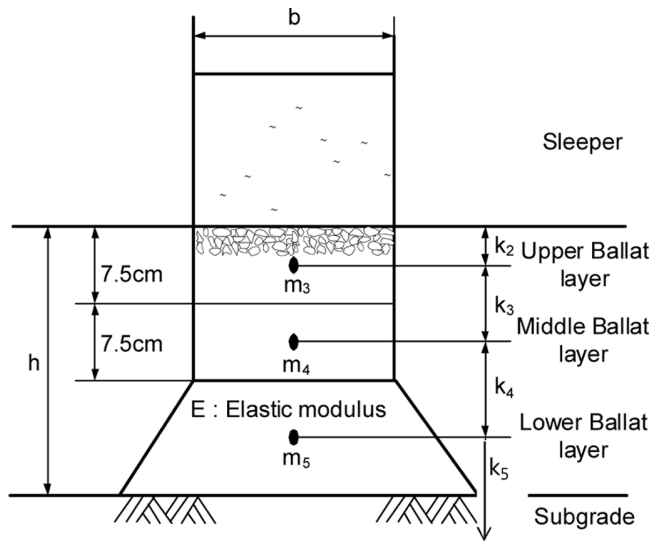

Fig. 2 Stress distribution of a ballasted track

$$
\begin{gathered}
h_{h}=h-0.15 \quad d_{b}=b+2 \times h_{h} \quad d_{1}=1+2 \times h_{h} \\
z_{1}=b \times 1+b \times d_{1}+d_{b} \times 1+3 \times d_{b} \times d_{1}, \\
z_{2}=2 \times b \times 1+b \times d_{1}+d_{b} \times 1+2 \times d_{b} \times d_{1}, \quad z_{s}=\frac{h_{h} \times z_{1}}{2 \times z_{2}} \\
g_{l 1}=\log \frac{\left(h_{h}+b / 2\right) \times l}{\left(h_{h}+l / 2\right) \times b}, g_{l 2}=\log \frac{\left(h_{h}-z_{S}+b / 2\right) \times l}{\left(h_{h}-z_{S}+l / 2\right) \times b} \\
d_{k 1}=k_{2}, \quad d_{k 2}=\frac{k \times(1-b)}{g_{l 2}}, \quad d_{k 4}=\frac{k \times(1-b)}{\left(g_{n}-g_{l 2}\right)}, \quad d_{k 5}=\frac{K \times d_{b} \times d_{1}}{2}
\end{gathered}
$$

\section{2 차륜과 레일의 접촉강성모형}

차륜/레일 접촉력은 Fig. 3과 같이 헤르쯔안스프링(Hertzian spring)을 통하여 전달되며 다음과 같이 나타내진다[15].

$$
F_{H}= \begin{cases}c_{H}\left(u_{w}-u_{r}-u_{o}\right)^{3 / 2}=K_{H}\left(u_{w}-u_{r}-u_{o}\right) & \text { if }\left(u_{w}-u_{r}-u_{o}\right)>0 \\ 0 & \text { else }\end{cases}
$$

식 (7)에서 $u_{w}$ 및 $u_{r}$ 는 각각 접촉위치에서 차륜 및 레일 변위이며, $u_{o}$ 는 접촉위치에서 차륜/레일 조도(the wheel/rail

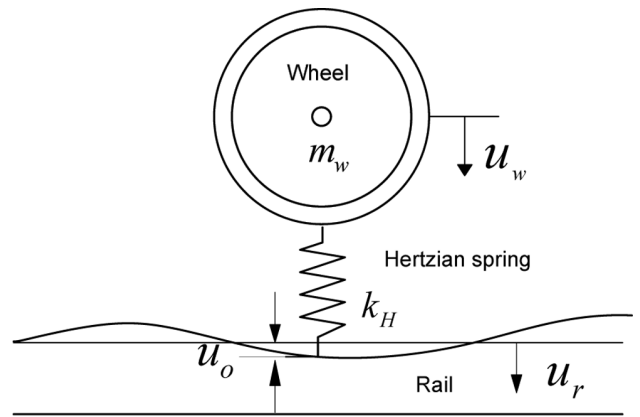

Fig. 3 Hertzian contact stiffness irregularity). 또한 $K_{H}$ 는 선형 헤르쯔안스프링강성(the linearized Hertzian spring stiffness)으로 다음과 같이 나타내진다.

$$
K_{H}=c_{H}\left(u_{w}-u_{r}-u_{0}\right)^{1 / 2}
$$

식 (7)에서 $c_{H}$ 는 레일과 차륜의 곡선반경과 재료의 성질 에 좌우되는 헤르쯔안 상수 (Hertzian constant)로서 다음 식 과 같이 구해진다.

$$
c_{H}=\left\{\frac{9}{32} \lambda^{2} A\left\{\frac{1-v^{2}}{E}\right\}^{2}\right\}^{-\frac{1}{2}}=\sqrt{\frac{32}{9}} \lambda^{-\frac{3}{2}} A^{-\frac{1}{2}}\left\{\frac{1-v^{2}}{E}\right\}^{-1}
$$

여기서, $E v$ 는 각각 차륜과 레일의 탄성계수 및 포아송비이 며, $A=1 / 2\left(1 / R_{w}+1 / R_{r}\right)$ 이고, $R_{w}, R_{r}$ 는 각각 차륜반경 및 레 일두부의 곡률반경이다. 한편 $\lambda$ 는 $\theta=\cos ^{-1}(B / A)$ 의 함수로서 $\theta$ 에 따라서 Table 1 과 같이 주어진다. 이때 $B$ 는 다음 식으 로 주어진다.

$$
B=\sqrt{1 / R_{1}^{2}+1 / R_{2}^{2}-2 \cos \phi / R_{1} R_{2}}
$$

여기서 $\phi$ 는 주곡률로 $1 / R_{1}, 1 / R_{2}$ 을 포함하는 면들의 사이 각 으로서 차륜이 직선레일에서 직진할 경우에는 $\phi=0$ 이 된다.

Table $1 \lambda$ value for $\theta$

\begin{tabular}{c|c|c|c|c|c|c|c|c}
\hline$\theta$ & $0^{\circ}$ & $10^{\circ}$ & $20^{\circ}$ & $30^{\circ}$ & $35^{\circ}$ & $40^{\circ}$ & $45^{\circ}$ & $50^{\circ}$ \\
\hline \hline$\lambda$ & - & 0.851 & 1.220 & 1.453 & 1.550 & 1.637 & 1.709 & 1.772 \\
\hline
\end{tabular}

\begin{tabular}{c|c|c|c|c|c|c|c|c}
\hline$\theta$ & $55^{\circ}$ & $60^{\circ}$ & $65^{\circ}$ & $70^{\circ}$ & $75^{\circ}$ & $80^{\circ}$ & $85^{\circ}$ & $90^{\circ}$ \\
\hline \hline$\lambda$ & 1.828 & 1.875 & 1.912 & 1.944 & 1.967 & 1.985 & 1.996 & 2.000 \\
\hline
\end{tabular}

\section{3 뜬침목 모델링}

침목과 도상 사이에 간극 $\left(u_{o}\right)$ 이 있을 경우 두 질점사이 상 호작용은 그림 Fig. 4와 같이 모델링 할 수 있으며, 두 질 점사이의 작용력은 두 질점의 상대변위로 그림 Fig. 5와 같 이 나타내진다. 이때 두 질점사이의 상호작용력은 분리 또 는 접촉여부에 따라 다음과 같이 해석 알고리듬 (Algorithm) 에 반영한다. 즉, 두 질점이 접촉하지 않을 경우 $\left(u=y_{2}-y_{3}-u_{0}\right)$ 는 강성 및 감쇠가 없는 것으로 하며, 두 질점이 접촉하는 경우 $\left(u=y_{2}-y_{3} \geq u_{0}\right)$ 는 간극이 없는 경우의 일반 강성 및 감쇠 요소로서 시스템 강성 및 감쇠행렬에 어셈블링(Assembling) 하되, 시스템 하중 벡터에 다음과 같이 간극에 의하여 발생 한 부가하중을 더한다.

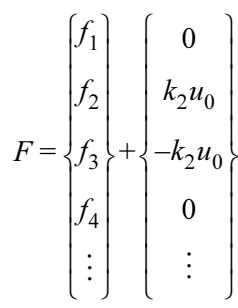




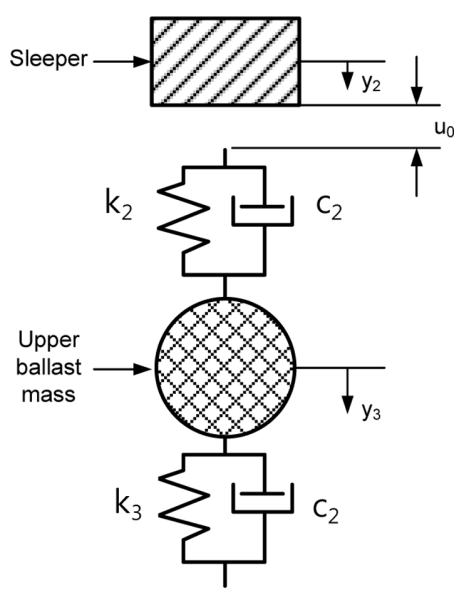

Fig. 4 Model of gap between sleeper and upper ballast layer

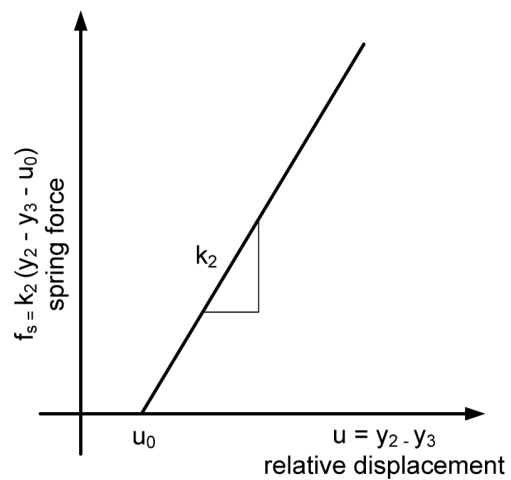

Fig. 5 Spring force between sleeper and upper ballast layer

\section{4 노반침하에 의한 궤도틀림 및 침목들뜸량 계산}

Fig. 6과 같이 노반이 침하한 경우 궤광은 자중에 의하여 아래로 처짐이 발생한다. 도상의 침하량이 클 경우에는 침 목이 도상에 닿지 않는 뜬침목이 발생하지만, 도상의 침하 량이 작을 경우에는 침목이 도상과 접촉하게 될 것이다. 따 라서 해석시 침목들뜸량은 궤광이 자중에 의하여 하방향으 로 처짐이 발생하였을 때 침목과 도상사이의 간극이라 할 수 있다. 또한 궤도틀림량은 궤광의 처짐에 의한 레일의 수직 변위로 볼 수 있다. 이들의 계산은 침목과 도상사이의 강성 력이 Fig. 5와 같이 비선형 거동을 보이므로 다음과 같은 과 정의 시행착오 방법으로 수행한다.

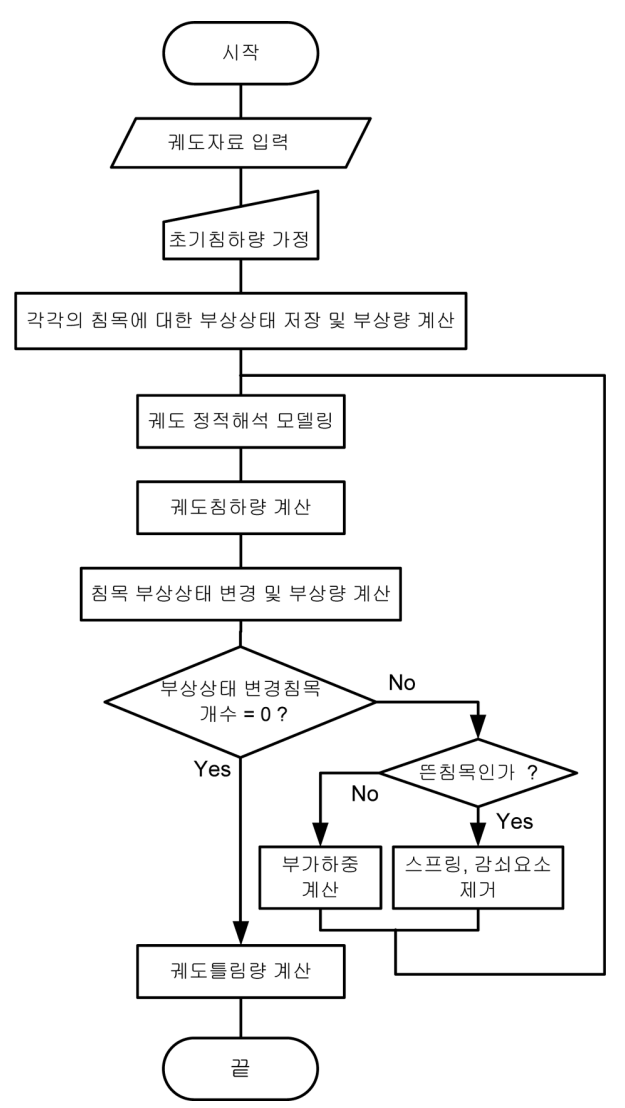

Fig. 7 Flowchart for calculation of gap on hanging sleepers

(i)초기에 궤광이 직선을 유지한다고(소성처짐이 발생하지 않았다고) 가정하고 초기 노반침하량을 침목들뜸량으로 보 아 뜬침목의 강성력을 고려하지 않고 궤광의 자중에 의한 처 짐량을 구한다. (ii) 자중에 의하여 처진 궤광의 변위와 초 기 노반침하량과 비교하여 침목의 부상여부를 판단한다. 이 들의 판단을 통하여 아직도 침목이 들뜬 경우는 전회 해석 처럼 강성력을 고려하지 않으나, 도상과 접촉하게 된 초기 의 뜬침목은 식 (11)의 부가하중을 고려하여 재해석한다. (iii) 이러한 해석을 반복해 가면서 각각의 침목이 들뜸 또는 접 촉상태를 일정하게 유지하는가를 판단한다. 모든 침목이 일 정한 상태에 오면 해석을 종료하고 이때의 침목들뜸량 및 레 일변위에 의한 궤도틀림을 구한다. 이상의 알고리즘을 흐름 도로 나타내면 Fig. 7과 같다.

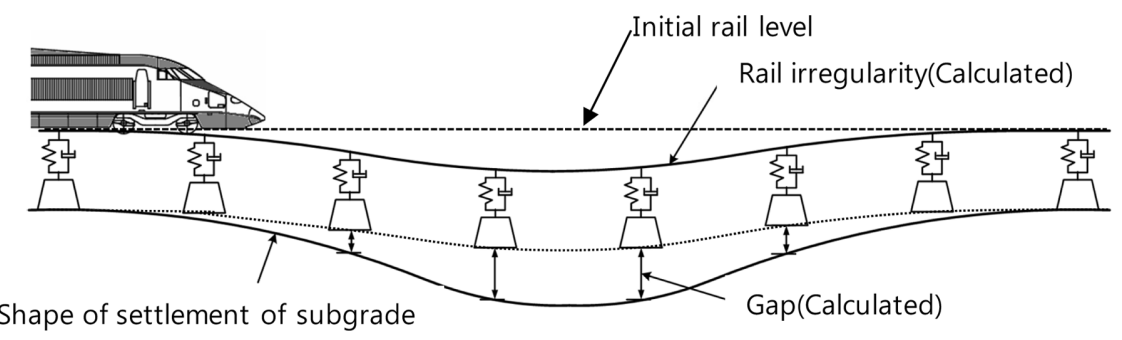

Fig. 6 Deflection of track due the settlement of subgrade 
Table 2 Dimensions and properties of track

\begin{tabular}{|c|c|}
\hline Characteristics & Value \\
\hline Rail type & 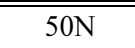 \\
\hline Radius of rail crown $(\mathrm{mm})$ & 300 \\
\hline Rail mass $(\mathrm{kg} / \mathrm{m})$ & 50.4 \\
\hline Rail bending stiffness $\left(\mathrm{kN} / \mathrm{m}^{2}\right)$ & $4.05 \times 10^{3}$ \\
\hline Rail pad stiffness $(\mathrm{kN} / \mathrm{m})$ & $6.0 \times 10^{4}$ \\
\hline Rail pad damping coef. $(\mathrm{kN} \cdot \mathrm{s} / \mathrm{m})$ & 98.0 \\
\hline Sleeper type & PC sleeper \\
\hline Sleeper bay $(\mathrm{m})$ & 0.6 \\
\hline Sleeper mass $(\mathrm{kg})$ & 130.0 \\
\hline Sleeper bottom area $\left(\mathrm{m}^{2}\right)$ & 0.36 \\
\hline Stiffness of ballast supporting sleeper $(\mathrm{kN} / \mathrm{m})$ & $1.19 \times 10^{6}$ \\
\hline Damping coef. of ballast supporting sleeper $(\mathrm{kN} \cdot \mathrm{s} / \mathrm{m})$ & 98.0 \\
\hline Upper ballast mass $(\mathrm{kg})$ & 65.4 \\
\hline Stiffness of ballast supporting upper ballast $(\mathrm{kN} / \mathrm{m})$ & $0.593 \times 10^{6}$ \\
\hline $\begin{array}{l}\text { Damping coef. of ballast supporting upper ballast } \\
(\mathrm{kN} \cdot \mathrm{s} / \mathrm{m})\end{array}$ & 980.0 \\
\hline Middle ballast mass $(\mathrm{kg})$ & 65.4 \\
\hline Stiffness of ballast supporting middle ballast $(\mathrm{kN} / \mathrm{m})$ & $0.540 \times 10^{6}$ \\
\hline $\begin{array}{l}\text { Damping coef. of ballast supporting middle ballast } \\
(\mathrm{kN} \cdot \mathrm{s} / \mathrm{m})\end{array}$ & 980.0 \\
\hline Lower ballast mass $(\mathrm{kg})$ & 118.6 \\
\hline Stiffness of ballast supporting lower ballast $(\mathrm{kN} / \mathrm{m})$ & $1.67 \times 10^{6}$ \\
\hline $\begin{array}{l}\text { Damping coef. of ballast supporting lower ballast } \\
(\mathrm{kN} \cdot \mathrm{s} / \mathrm{m})\end{array}$ & 980.0 \\
\hline Stiffness of subgrade $(\mathrm{kN} / \mathrm{m})$ & $3.0 \times 10^{4}$ \\
\hline Damping coef. of subgrade $((\mathrm{kN} \cdot \mathrm{s} / \mathrm{m})$ & 980.0 \\
\hline
\end{tabular}

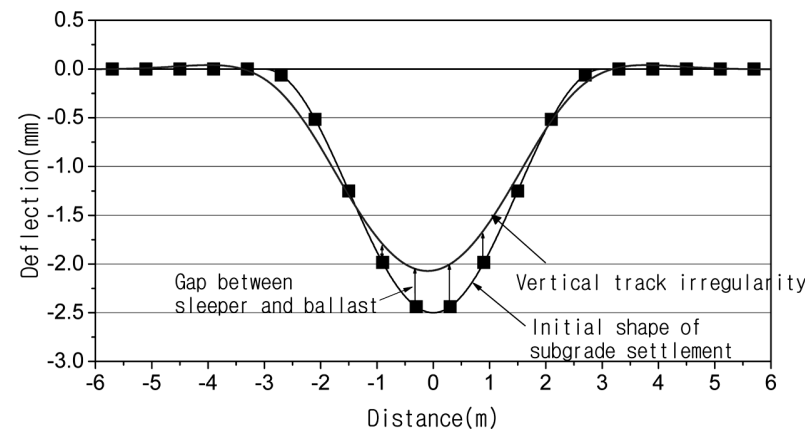

Fig. 8 Shape of deflection of track due to subgrade settlement

Table 2의 제원을 갖는 궤도시스템에서 초기의 노반침하 를 파장 $6 \mathrm{~m}$, 진폭이 $2.5 \mathrm{~mm}$ 인 정현파로 가정할 때 앞서 제 시한 계산과정을 통하여 얻어진 침목들뜸량 및 궤도틀림을 계산하였다. 계산이 수렴되는 시행착오 횟수는 4회 정도로 서 효율적으로 초기 노반침하에 따른 궤도틀림 및 침목들뜸
량이 계산되는 것을 알 수 있었다. 한편 계산결과를 나타낸 Fig. 8로부터 노반침하에 의하여 발생하는 궤도틀림은 노반 의 처짐 형상 및 크기와 비슷하게 발생하나 레일의 휨강성 때문에 약간의 차이가 발생하는 것을 알 수 있다.

\section{3. 뜬 침목을 고려한 차량/궤도 상호작용 해석기법의 검증}

본 연구에서 개발한 뜬침목을 고려한 차량/궤도 상호작용 해석기법을 검증하기 위하여 일본 철도기술연구소의 Ono 등 [11]이 해석한 바 있는 뜬침목 구간의 차량/궤도 상호작용해 석 예제와 동일한 예제해석을 수행하여 두 결과를 비교함으 로써 검증하였다.

차량/궤도 해석모형은 Fig. 1과 같고 해석에 사용된 궤도 의 제원 및 물성치는 Table 2와 동일하며 차량의 제원 및 물 성치는 Table 3과 같다. 또한 초기 노반침하형상은 Fig. 8에 서 제시한 것과 동일한 형상의 파장 $6.0 \mathrm{~m}$, 진폭 $2.5 \mathrm{~mm}$ 의 Sine파와 곡선이다.

Table 3 Dimensions and properties of train

\begin{tabular}{l|c}
\hline \multicolumn{1}{c|}{ Train type } & Shinkansen \\
\hline \hline Mass of half car body $(\mathrm{kg})$ & 7862.0 \\
\hline Stiffness of secondary suspension $(\mathrm{kN} / \mathrm{m})$ & 251.2 \\
\hline Damping coef. of secondary suspension $(\mathrm{kN} \cdot \mathrm{s} / \mathrm{m})$ & 45.3 \\
\hline Mass of bogie frame $(\mathrm{kg})$ & 1531.0 \\
\hline Stiffness of primary suspension $(\mathrm{kN} / \mathrm{m})$ & 1180.2 \\
\hline Damping coef. of primary suspension $(\mathrm{kN} \cdot \mathrm{s} / \mathrm{m})$ & 39.2 \\
\hline Rigid wheel base $(\mathrm{m})$ & 2.5 \\
\hline Wheelset mass $(\mathrm{kg})$ & 827.0 \\
\hline Wheel diameter $(\mathrm{mm})$ & 860.0 \\
\hline
\end{tabular}

Fig. 9는 본 연구에서 제시한 해석기법을 사용하여 얻은 차륜/레일 접촉력과 침목/자갈도상 접촉력을 일본철도총합 기술연구소의 Ono 등[11]이 제시한 해석결과를 함께 나타 낸 것이다 이들 해석결과를 비교하면 비교적 두 결과가 거 의 잘 일치하는 것을 알 수 있는데 일부 구간에서는 다소 차이가 있는 것을 알 수 있다. 본 연구에서는 차량 1 량 전 체를 모델링 한데 반하여 Ono의 연구에서는 반차체만을 모 델링 함으로써 차체(Car body)의 피칭모션(Pitching Motion) 이 고려되지 않았다. 특히 궤도모델은 양쪽 모두 동일하게 5 층으로 모델링 하였으나 레일모델에 있어서는 Ono는 모 드중첩법(Mode superposition)으로 모델링 함으로써 충격하 중에 의한 고주파진동을 나타내는데 다소의 어려움이 있었 던 것에 반하여 본 연구에서는 국부의 고주파 진동을 비교 적 잘 나타낼 수 있는 유한요소로 직접 모델링 하였다. 이 러한 모델링의 차이가 해석결과의 차이를 유발한 것으로 판 단된다. 


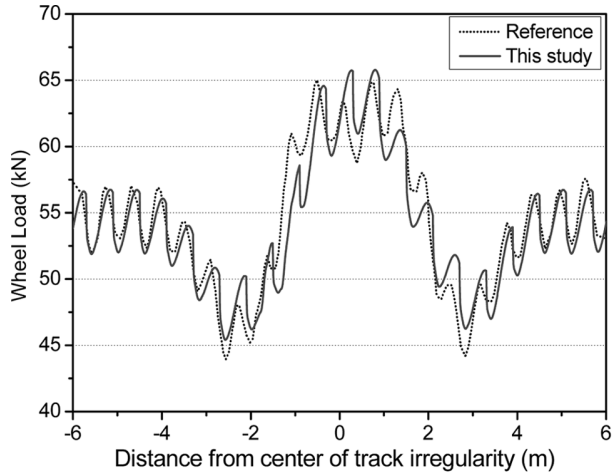

(a) Wheel contact load

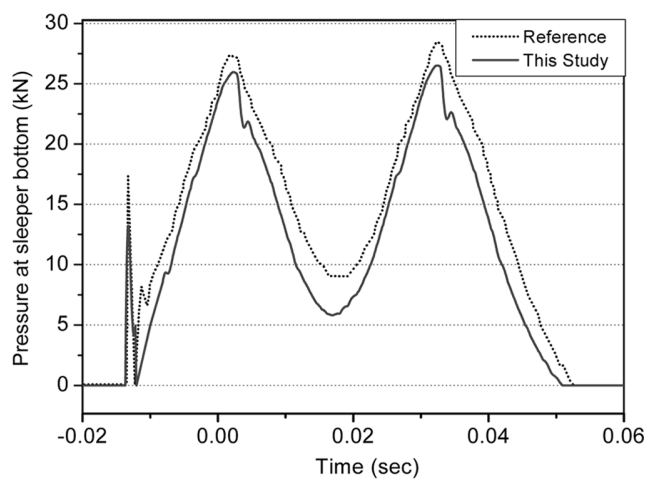

(b) Contact force between sleeper and ballast

Fig. 9 Comparison of results by the present method and Ono[11]

\section{4. 결 론}

본 연구에서는 고속철도 궤도의 유지보수에서 중요하게 부 각되는 뜬침목 문제를 분석할 수 있는 차량 및 궤도의 상 호작용해석 기법을 개발하고 검증하였다.

침목 하면의 도상이 침하하여 침목과 도상이 분리되는 경 우에 궤광의 자중에 의하여 발생하는 초기 궤도면틀림량과 잔여 들뜸량을 효율적으로 계산할 수 있는 정적 비선형 해 석기법을 개발하였으며, 초기궤도틀림 및 뜬침목이 있는 구 간을 차량이 통과할 때 차량 및 궤도의 거동을 해석할 수 있 는 동적 차량/궤도 상호작용 해석기법을 개발하였다. 개발된 해석기법을 검증하기 위하여 일본 철도총합연구소의 Ono 등 [11]이 수행한 연구와 본 해석기법의 계산치를 비교한 결과 두 값이 대체로 일치함을 확인할 수 있었다. 본 연구를 통하 여 개발된 궤도해석프로그램은 뜬침목 발생 구간의 유지보 수 방법 개선 등 실용적으로 유용한 정보를 제공하고, 궤도 틀림 발생구간의 궤도동적거동을 해석하는 데 유용한 자료 가 될 것으로 사료된다. 향후 뜬침목 구간의 현장계측 및 실 험적 연구와 사례조사 연구 등의 후속 연구를 통하여 뜬침 목의 발생원인과 거동특성 규명을 위한 추가 연구가 필요하다.

\section{참고문헌}

[1] W. Zhai, Z. Cai (1997) Dynamic interaction between a lumped mass vehicle and a discretely supported continuous rail track, Computer \& structures, 63(5), pp. 987-997.

[2] Y.Q. Sun, M. Dhanasekar (2002) A dynamic model for the vertical interaction of the rail track and wagon system, Int. J. of Solids and Structures, 39(5), pp. 1337-1359.

[3] X.S. Jin, Z.F. Wen, K.Y. Wang, et al (2006) Three-dimensional train-track model for study of rail corrugation. $J$. of Sound and Vibration, p. 293.

[4] G. Xie, S.D. Iwnicki (2008) Simulation of wear on a rough rail using a time-domain wheel-track interaction model. Wear, 265, pp. 1572-1583, pp. 830-855.

[5] R.G. Dong, S. Sankar, R.V. Dukkipati (1994) A fintie element model of railway track and its application to the wheel flat problem, Proc. Instn Mech. Engrs, Part F: J. of Rail and Rapid
Transit, 208, pp. 61-72.

[6] S.C. Yang (2011) Investigation of the maintenance criteria for the rail surface defects in high-speed railways, Journal of Korean Society for Railway, 14(6), pp. 535-544.

[7] K. Koro, K. Abe, M. Ishida, T. Suzuki (2004) Timoshenko beam finite element for vehicle-track vibration analysis and its application to jointed railway track, Proc. Instn Mech. Engrs, Part F ? J. of Rail and Rapid Transit, 218, pp. 159-172.

[8] A. Lundqvist, T. Dahlberg (2005) Load impact onrailway track due to unsupported sleepers, Proc. Instn Mech. Engrs, Part F: J. of Rail and Rapid Transit, 219, pp. 67-77.

[9] Y. Bezin, S.D. Iwnicki1, M. Cavalletti, E. deVries, et al (2009) An invsstigation of sleeper voids using a flexible track model integrated with railway multi-body dynamics, Proc. Instn Mech. Engrs, Part F: J. of Rail and Rapid Transit, 223, pp. 597-607.

[10] S.G. Zhang, X.B. Xiao, Z.F. Wen, X.S. Jin (2008) Effect of unsupported sleepers on wheel/rail normal load, Soil Dynamics and Earthquake Engineering, 28, pp. 662-673.

[11] S. Ono, M. Ishida, M. Uchida (2001) Prediction of the growth of track irregularity using track dynamic model, RTRI report, 15(4), pp. 39-44.

[12] S.C. Yang (2009) Enhancement of the finite-element method for the analysis of vertical train-track interactions, Proc Proceedings of the Institution of Mechanical Engineers, Part F: Journal of Rail and Rapid Transit, 223, pp. 609-620.

[13] W. Zhai, Z. Cai (1997) Dynamic interaction between a lumped mass vehicle and a discretely supported continuous rail track, Computer \& structures, 63(5), pp. 987-997.

[14] X. Lei, N.A. Noda (2002) Analyses of dynamic response of vehicle and track coupling system with random irregularity of track vertical profile, J. of Sound and Vibration, 258(1), pp. 147-165.

[15] R.V. Dukkipati (2000) Vehicle Dynamics, CRC Press, USA.

[16] S.C. Yang, E. Kim (2012) Effect on vehicle and track interaction of installation faults in the concrete bearing surface of a direct-fixation track, $J$. of Sound and Vibration, 331(1), pp. 192-212.

접수일(2011년 9월 16일), 수정일(2011년 12월 26일), 게재확정일(2012년 3월 16일) 